\title{
Integration of Data-Driven Process Re-Engineering and Process Interdependence for Manufacturing Optimization Supported by Smart Structured Data
}

\author{
Md Ashikul Alam Khan ${ }^{1, *}$, Javaid Butt ${ }^{1}{ }^{\mathbb{D}}$, Habtom Mebrahtu ${ }^{1}$, Hassan Shirvani ${ }^{1}$, \\ Alireza Sanaei ${ }^{1}$ and Mohammad Nazmul Alam ${ }^{2}$ \\ 1 School of Engineering and the Built Environment, Anglia Ruskin University, Bishop Hall lane, Essex, \\ Chelmsford CM1 1SQ, UK \\ 2 Department of Computer Science and Engineering, Royal University of Dhaka, Dhaka-1213, Bangladesh \\ * Correspondence: md.khan@anglia.ac.uk
}

Received: 30 June 2019; Accepted: 15 August 2019; Published: 17 August 2019

\begin{abstract}
Process re-engineering and optimization in manufacturing industries is a big challenge because of process interdependencies characterized by a high failure rate. Research has shown that over $70 \%$ of approaches fail because of complexity as a result of process interdependencies during the implementation phase. This paper investigates data from a manufacturing operation and designs a filtration algorithm to analyze process interdependencies as a new approach for process optimization. The algorithm examines the data from a manufacturing process to identify limitations through cause and effect relationships and implements changes to achieve an optimized result. The proposed cause and effect approach of re-engineering is termed the Khan-Hassan-Butt (KHB) methodology, and it can filter the process interdependencies and use those as key decision-making tools. It provides an improved process optimization framework that incorporates data analysis along with a cause and effect algorithm to filter out the process interdependencies as an approach to increase output and reduce failure factors simultaneously. It also provides a framework for filtering the manufacturing data into smart structured data. Based on the proposed KHB methodology, the study investigated a production line process using the WITNESS Horizon 22 simulation package and analyzed the efficiency of the proposed approach for production optimization. A case study is provided that integrated the KHB methodology with data-driven process re-engineering to analyze the process interdependencies to use them as decision-making tools for production optimization.
\end{abstract}

Keywords: process re-engineering; manufacturing processes; structured data; smart structured data; cause and effect re-engineering; process optimization framework; process interdependencies; cause and effect algorithm

\section{Introduction}

Process re-engineering in manufacturing industries refers to changes in the manufacturing process and could be a significant change in business environments, from technology to culture [1]. There is always a set objective of process re-engineering within a manufacturing organization, which is increased productivity, flexibility and cost efficiency by changing core business procedures and adapting by eliminating unproductive layers and activities in the organization [2]. Process re-engineering often includes changes in the organization (from functional to cross-functional) and technological implementation to improve data trafficking and decision-making.

The ability to access, analyze and manage vast volumes of data while rapidly evolving the information architecture is increasing complexity [3]. Many manufacturing organizations are researching 
solutions to improve their manufacturing quality while reducing support costs by improving defect tracking and improving forecasting abilities to optimize supply chains, thus leading to overall operational efficiency improvements. These manufacturing and operational improvements, combined with achieving a favorable customer experience, remain crucial to driving success. Gaining new insights into information is critical for maintaining or growing market shares. As manufacturing companies are becoming larger and more diverse, the types of data that must be managed become even more complex. External data from social media outlets and supplier network channels provide a huge influx to augment existing data that combine sensors and machine data coming from the production line. To adapt and evolve within a challenging environment, manufacturing organizations need to bring changes to structure and strategy with fast and effective decision-making.

Modern manufacturing industries are going through a data-driven revolution that is transforming traditional manufacturing into a highly optimized manufacturing process [4]. Along with technological advancements for smart manufacturing facilities, industries are focusing on creating manufacturing intelligence from real-time data to support decision-making for the entire organization [5]. The development of advanced digital electronics and computer integrated systems has delivered technologies such as cyber-physical systems (CPSes) and the internet of things (IoT), which can collect and deliver real-time data from an entire manufacturing organization $[4,6,7]$. The biggest challenge for manufacturing industries is not producing, but handling data appropriately. This can lead to potential applications of using this data to optimize manufacturing output and eliminate inefficiency [4].

The main objectives of process re-engineering (PR) in manufacturing industries are to bring efficiency and increase productivity through changes in processes or functions that are unprecedented given the appearance of new technologies and globalization [8]. These changes are building up inefficiencies, leading to strategic failure [9]. Process re-engineering in a manufacturing organization is more complex, as it requires the identification of factors that affect the process from start to end [10]. There are many factors that influence fundamental rethinking and radical redesign in bringing about improvement [8]. The failure factors and success factors of a process can be described as the interdependent issues that arise while implementing changes [10]. Most of manufacturing processes are reciprocal or sequential, which means that a change in one step will affect the subsequent or entire process $[10,11]$. Before implementing changes, an organization needs to identify the interdependent issues that affect the performance or productivity of subsequent functions. Process interdependencies can be identified through analysis of a process, and this paper discusses the process of identification of interdependencies through the integration of data-driven process re-engineering [10] and cause and effect algorithms.

This paper will analyze the interdependencies caused by changing a manufacturing process and will provide a cause and effect algorithm and integrate it with data-driven process re-engineering [10]. The proposed method is termed the Khan-Hassan-Butt (KHB) method and can identify process interdependencies and optimize the process simultaneously. A case study (Section 4) was utilized to implement the newly proposed method, and the results were compared to our previous work [10] to establish the superiority of the KHB method. The paper is divided into sections: Section 2 presents a literature review of the existing approaches, Section 3 provides information about the proposed KHB method and Section 4 describes the case study.

\section{Literature Review}

\subsection{Manufacturing Processes and Limitations}

During the 1970s, it became a requirement to establish time-phased priority planning approaches to manage production and inventory. Material requirements planning (MRP) was initiated among the industries during that time [11]. MRP is based on four key elements (a bill of materials, the master production schedule (MPS), the production cycle time and the supplier lead time) to predict the required materials for future production. Within technological development during the 1980s, to meet global 
demand, the traditional push system was taken over by pull production. A Japanese manufacturing company, Toyota, in the 1970s initiated the pull production system to keep the continuous flow of the production line intact. The main approach of the pull production system was to develop a production system that had zero inventory and waste elimination throughout the supply chain. During this time, industries were trying to eliminate delays and waste in the supply chain to bring about more efficiency [12].

One of the recent manufacturing processes that industries have adopted is lean manufacturing (LM). LM focuses on efficiency with minimized costs to increase productivity, improve quality and reduce lead time $[3,13,14]$. LM is appropriate for an environment where mass productions are required for a repeated pattern, which has a major defect in the changing environment of the market and productions. Additive manufacturing is an excellent technology that can fit in to LM and considers the reduction of costs as the major selling point $[3,15,16]$. The concept of agile manufacturing (AM) has also had a considerable impact on manufacturing industries and can be termed an evolution of the embedded system of the manufacturing of the 21st century due to a global competitive free market economy. During the 20th century, the focus of industries was cost-cutting [17]. AM can be derived from a business concept that can integrate an organization's resources, assets and technology in a meaningful and efficient way to make the manufacturing process more agile and flexible [18]. The development of information technology has created greater efficiency in responding to customer requirements and meeting total manufacturing needs [19]. These aspects work well with AM and LM [20]. The possibility of integrating data analysis can create a greater opportunity to meet customer requirements with real-time decision-making. On the other hand, process re-engineering (PR) is an approach that can be used to improve LM and AM. It is referred to as the restructuring of the organizational process through a specific management strategy focusing on radical ground-up procedures [10]. According to the literature, PR is comprised of $[21,22]$ the following:

- Input (data related to customer inquiries for service or materials for operations);

- Process (a process related to data acquisition or materials); and

- Output (expected outcomes).

Dependency and rational issues of process re-engineering (PR) can be considered to be the complexity that arises during PR implementation that enhances process efficiency or creates obstacles. In most methodologies and models of PR, every step is an output of a management strategy that works as an input or requirement of subsequent steps. Hammer and Champy [22] described PR as a contemporary measure to achieve improvements in performance such as cost, service and quality. The main reason for PR failure is the high expectation of achievement and failure due to improper implementation [23,24]. For successful implementation of PR, proper communication in the workforce, knowledge of radical changes, empowerment of the employees, strong leadership and adequate resources are required [24]. The dependency issues of PR are the factors that are strongly related to the management and strategy of an organization. These are sets of regulations and their practice that drive the PR effort toward success or failure. The PR methodology and model used in a PR project have their own dependency and rational issues. PR dependency and rational issues based on their implementation level can be classed as success or failure factors that require identification during PR project implementation $[20,25]$.

\subsection{Success Factors for Business Process Re-Engineering}

The success factors of PR can be ascertained through different methodologies. Herzog, Polazner and Tonchia suggested success factors to be the guarantors of successful PR implementation, and a profit cannot be guaranteed without PR working out properly [26]. MC Adam and O'Hare analyzed, revealed and suggested the efficient roles of top management, employee commitment and empowerment, communication and a collaborative working environment as the most important success factors for the United Kingdom public sector [27]. Based on different business process re-engineering (BPR) 
methodologies, success factors can be divided into main categories and subcategories. The main categories include the organizational structure and division, and the subcategories are the activities. Based on the four BPR methodologies and models described in the literature [22,23,25-27], a framework of the BPR critical success factors is shown in Figure 1.

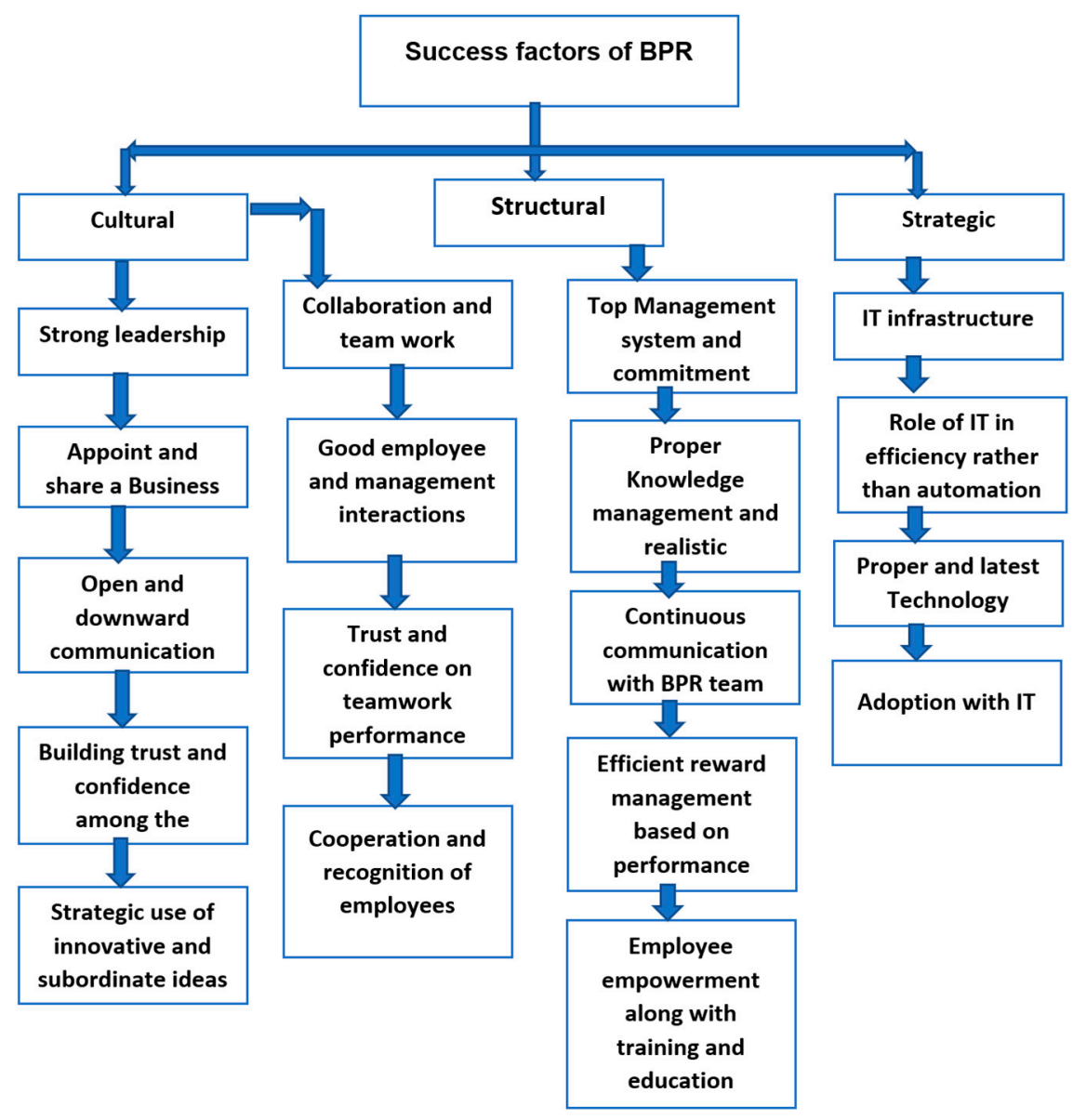

Figure 1. Critical success factor of process re-engineering (PR).

Figure 1 shows different categories of BPR success factors derived from different authors [22-27] in terms of cultural, structural and strategic influences. These factors play an important role in successfully achieving BPR objectives. An analysis of different authors [22-27] showed that cultural, structural and strategic factors such as strong leadership with open and downward communication, collaboration, a management system and IT (Information Technology) infrastructure are the most important success factors for successful process re-engineering implementation in manufacturing sectors of the UK. The success factors of BPR are derived from cultural, structural and strategic practices that are adopted by organizations while going through the BPR implementation phase [28].

\subsection{BPR Failure Factors}

The failure factors of BPR are normally seen as the resistance in the way of successful BPR implementation. These factors vary from company to company and case to case. However, some common factors have been derived by researchers over the years. Process re-engineering requires a clear vision and values, with the coordination of people, processes and technology [29]. In most organizations, management is quite rigid in bringing changes, and thus it fails to harmonize the integration of key success factors. One of the major failure factors in BPR is organizational culture and organizational rigidity to change. Lack of communication drives BPR initiatives to face cross-functional dependencies [10] that are reciprocal to each other. Magutu, Nyamwange and Kaptoge mentioned 
manufacturing and human resources, especially large working groups and the practice of cooperation, as success or failure factors of BPR [30]. Most authors have mentioned the failure of implementation as the major factor in BPR being unsuccessful [22-27,29,30]. In terms of organizational structure and strategy, high expectations without implementation capability, a lack of knowledge management and improper methodology are the major hindrances for success. Figure 2 shows BPR failure factors in terms of culture, structure and strategy. It identifies the major hindrances to successful BPR implementation according to different authors [22-27]. Most authors have mentioned IT infrastructure as a success factor for BPR. However, without choosing the right methodology and proper implementation capability, IT infrastructure will only add more cost.

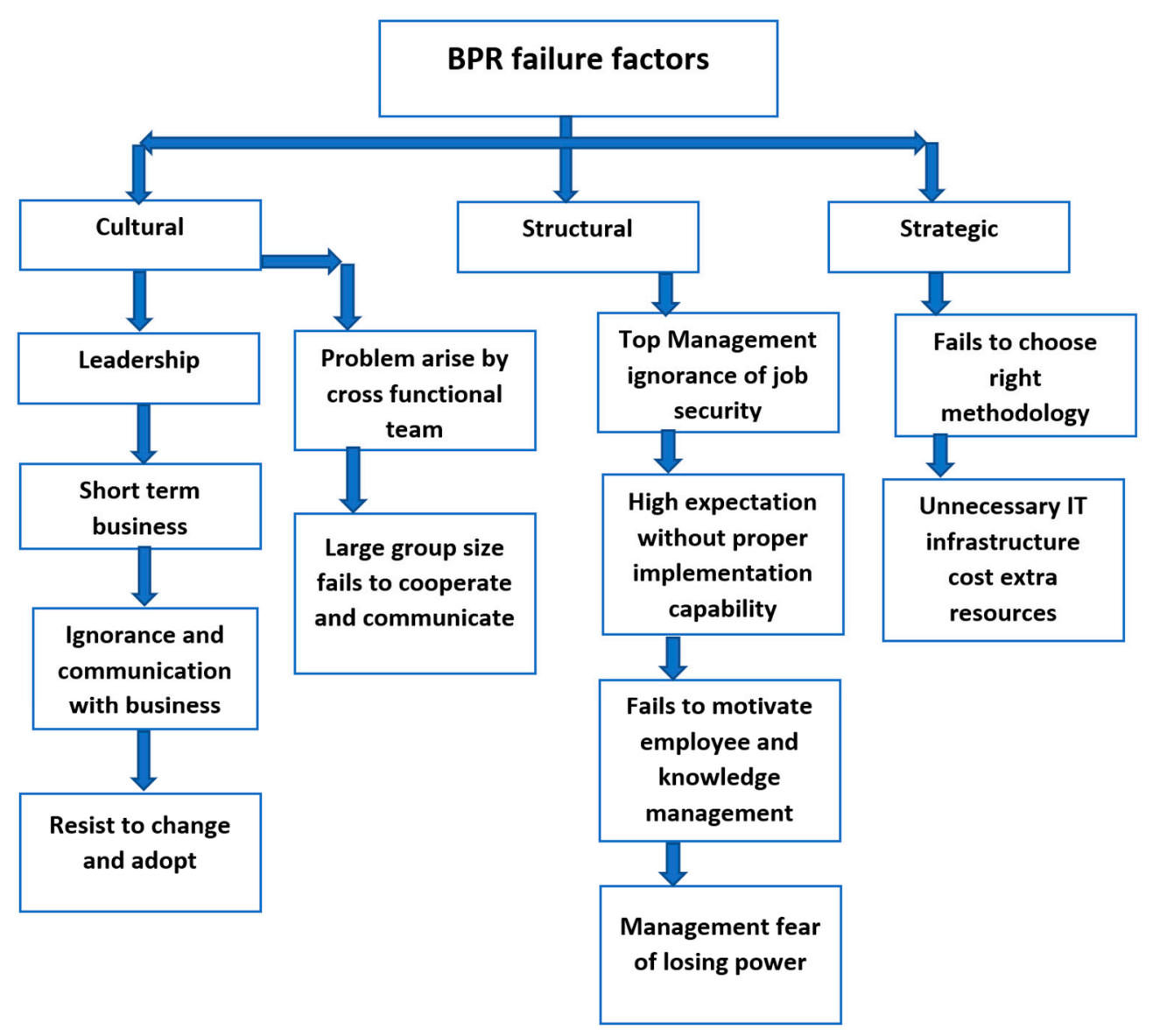

Figure 2. Critical failure factors of process re-engineering.

\subsection{Process Interdependencies}

Process interdependencies refer to an understanding of how different units or steps of a process or organization depend on the performance of others. Cross-functional dependencies affect manufacturing and organizational process efficiency [30]. There are three types of interdependencies that describe the intensity of interactions within an operational process or organization [11]. They are pooled, sequential and reciprocal.

Pooled interdependencies are operational where the functions of a unit are separate from others and may not directly depend on each other. This type of process has almost a blind dependency on performances, and failure in a step can lead the entire process to failure. On the other hand, the sequential interdependencies are created while the output of a process directly manipulates the performances of others or the overall process. A manufacturing process and assembly line are perfect examples of where sequential interdependencies exist. Reciprocal interdependencies are the ones where the outputs of units or departments become the inputs of the subsequent units or departments. 


\subsection{Structured Data and Manufacturing Process Integration}

The integration of structured data (SD) into manufacturing process re-engineering (MPR) can open new opportunities for intelligent sensing and decision-making, which is time-consuming when executed by humans [31]. The successful operation of a manufacturing process using SD analysis depends on the access to and management of organizational data, increasing the quality of manufacturing and reducing the costs simultaneously [32]. Along with the fast pace of manufacturing industries, typical data are becoming larger and divisive, and hence more complex. Thus, organizations need to manage both interorganizational and external data (e.g., supplier networks, social media and outlet data) to carry on making appropriate decisions. Data analysis enables organizations to have improved insight into the organizations' operations [33].

Manufacturing industries use data from warehouses, intelligent business tools and techniques to analyze operations, supply chain management, customer requirements and demands [34]. Through the integration of data and process re-engineering, it is possible to achieve greater efficiency in terms of agility. For the purposes of agility, manufacturing data can be used to deal with key business challenges and customer support. Integrating data-driven process re-engineering can open new opportunities for efficient plant operations and production through analyzing manufacturing data from sensors, combined with critical statistical analysis, to optimize production and operation [10]. In the case of supply chains and risk management, finding process interdependencies through data-driven PR can minimize risk through prevalent sensor data from machines, transportation and the supply chain.

\section{Proposed KHB Methodology}

The main objective of this research was to incorporate a new cause and effect algorithm along with data-driven process re-engineering [10] (termed the KHB method) to increase the efficiency of operations and optimize production. The KHB methodology is an integration of data-driven process re-engineering (proposed by the authors in Reference [10] and shown in Figure 3) and a cause and effect algorithm (proposed by the authors in this paper and shown in Figure 4). This combination intends to provide a better understanding of process interdependencies and provide an optimized output. The KHB method identifies process interdependencies and used them as decision-making tools to increase productivity. Section 3.1 discusses the data-driven process re-engineering (DDPR) approach, whereas Section 3.2 explains the cause and effect algorithm (CEA).

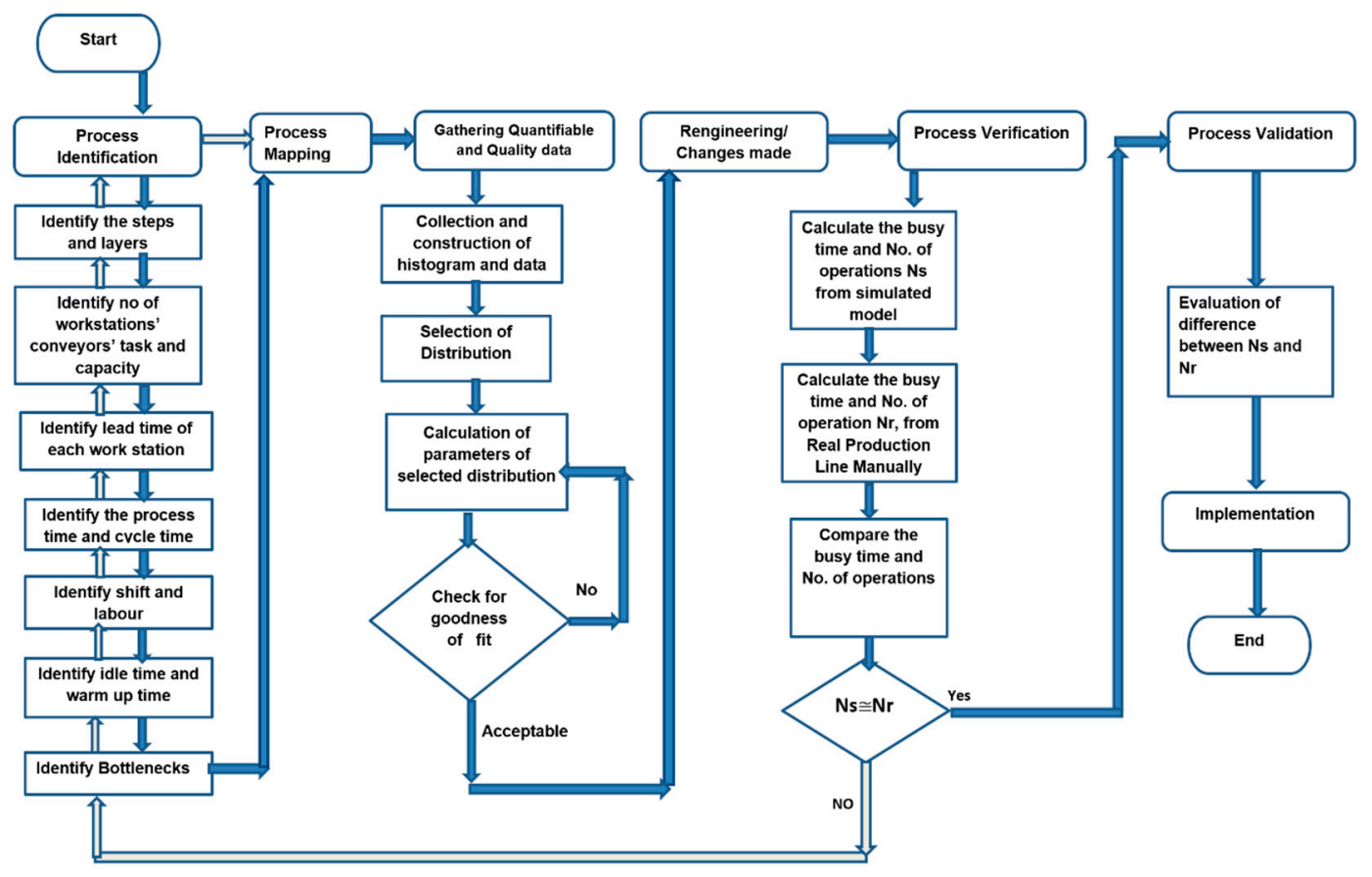

Figure 3. Data-driven process re-engineering (DDPR) and verification technique. 


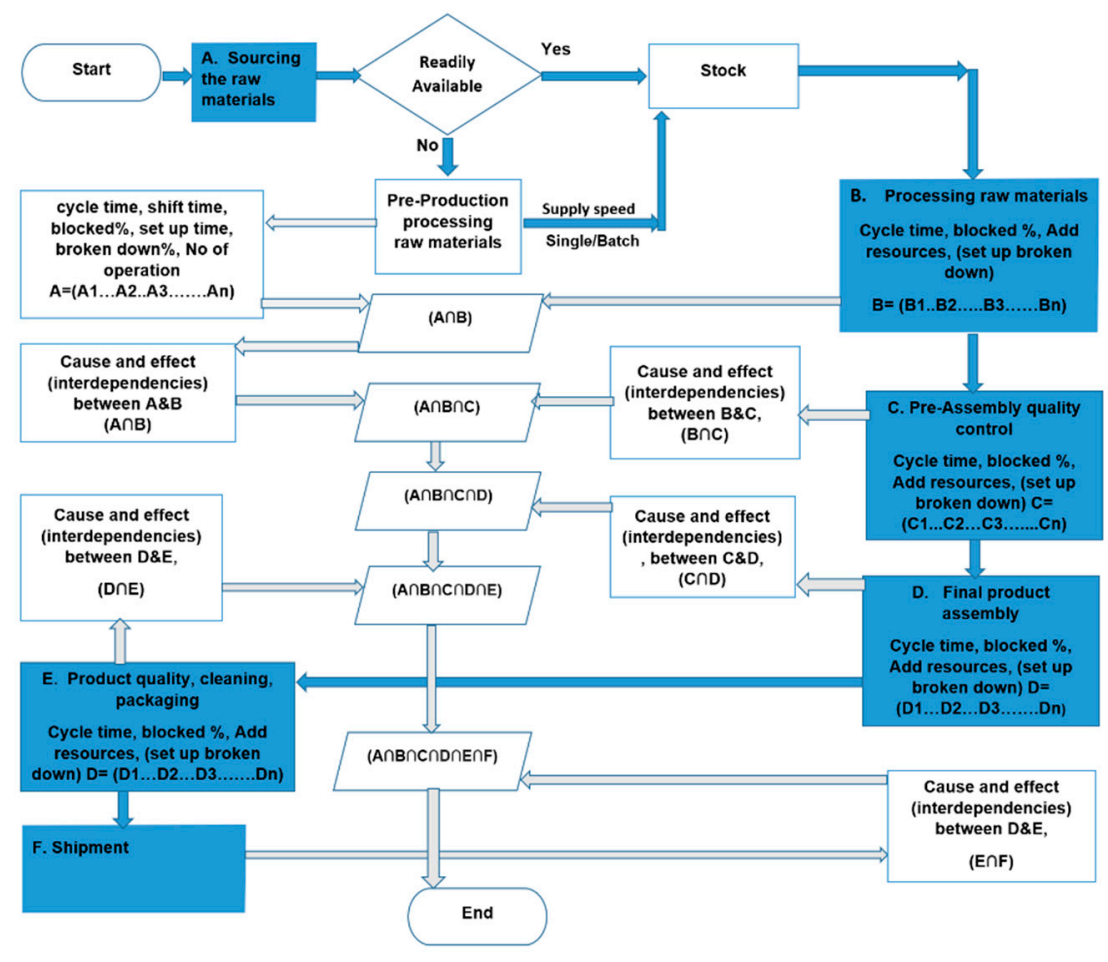

Figure 4. Cause and effect algorithm (CEA) structure.

\subsection{Data-Driven Process Re-Engineering (DDPR)}

To be successfully implemented, PR efforts require accurate information about an organization. A PR effort must have a contingency plan for the process implementation phase. The risk of failure in PR will significantly increase in the absence of some strategic steps that are essential in different phases of implementation. Manufacturing organizations often identify the value of traditional processes being achieved through long-term experiences with organizational structure. During the implementation phase of PR, organizations must have a contingency plan for dependency and rational issues. Data-driven PR uses data and simulations for process identification and mapping. It incorporates a verification stage with the re-engineering phase through a comparison of simulations and existing models. Once the process has been verified, the re-engineering phase runs a simulation with the required changes based on the collected data and analyzes the outcome through a goodness-of-fit test. This methodology tends to decrease the risk of failure by simulating the possible outcomes before implementation. The structure of the data-driven process re-engineering approach is described in Figure 3 and is based on the authors' previous work [10]. The subsequent sections, Sections 3.1.1-3.1.3 describe the working mechanisms of DDPR.

\subsubsection{Process Mapping and Identification}

Process identification represents the working procedure of a particular or generic manufacturing process. Process identification refers to the operation management of the manufacturing process. Once the operation management is identified, the process can be mapped based on the data collected from the shop floor. Process mapping defines the activity of a certain business entity. It shows that every step of a process should be executed to a certain standard. The aim of the design and validation of process mapping and identification is as follows:

- A generic model for process mapping and validation;

- Hypotheses and equations for process verification and validation.

Process mapping and identification aims to identify the process of a manufacturing system, which is the first step of data-driven process re-engineering, as shown in Figure 3. Along with the structure of 
the process, it identifies the aims based on the objectives of re-engineering initiatives. Identification of the process incorporates steps and layer identification, the identification of each working station and lead time, the process cycle time, shifts and labor and (most importantly) bottlenecks in the process. Identification and mapping of the process leads toward the data that will be required for the analysis of the process to find out the rationale and dependency issues.

\subsubsection{Gathering Quantifiable and Quality Data}

The quantifiability and quality of data could be a major hindrance in establishing an accurate model if they are not collected accurately. According to Bank and Carson [34,35], if the collected data are incorrect and analyzed inappropriately and do not represent the environment, then the simulation data will be misleading and damaging. Inaccurate data could lead to inappropriate analysis, which will provide an unrealistic and misleading simulation output.

\subsubsection{Model Verification Technique}

For model verification, the elements of the model were compared by checking the number of operations. Based on the busy time of machines, the number of operations was computed and compared to the number of operations from the simulations. The verification was performed according to the following equations.

Equations:

Suppose

Total number of units of operation(simulation) $=\mathrm{Ns}$

Busy time of Machines $=n \%(n=0,1,2, \ldots, 100)$

Mean of distribution of machine cycle time $=t \min$

Working time $=T \min =\{$ no. of shifts $\times$ no. of days of operation $\times($ shift length $\times 60)\}$

No of operations $\mathrm{Nr}=$ (machine busy time ${ }^{*}$ working time)/machine cycle time

$=(n \times T \mathrm{~min} / \mathrm{min})$ units

Now if the $N r \cong N s$, the simulation samples will be verified.

\subsection{Cause and Effect Algorithm}

The interdependencies in manufacturing processes can be reciprocal and sequential, which means that the output of one unit is used as the input of the next and the failure of one unit will have a strong impact on the entire process. The manufacturing process can be divided into some major units, which can be analyzed to identify the reciprocity and sequence of interdependencies. These units form the basis for the CEA, as follows:

1. Sourcing the raw materials;

2. Processing the raw materials;

3. Preassembly quality control;

4. Assembly line (final product);

5. Final check, quality, reworking, packaging and cleaning;

6. Shipment.

The production process was divided (but not limited to) into six major functions considering sequential PI (process interdependency), as shown in Figure 4. In any production line, any of the functions can be absent or have more units. The KHB methodology filters the interdependencies based on the units that are present in the process. The subunits facilitate any production process to fit the methodology. The process continuously filters out the interdependencies and feeds them back to the process as a set of decision-making tools that can eventually be used for optimizing production output and reducing failure factors in PR implementation. The data filtered out of the structured data are termed smart data, which can facilitate optimization with decision-making tools. The algorithm was 
integrated with data-driven process re-engineering [10] to analyze whether it could provide better output. This forms the basis for the KHB methodology.

The KHB methodology takes every change made in the current and previous functions into consideration to measure whether it is cross-functional or not. It breaks down the manufacturing process into sets and subsets and stores the changes made as PI. The changes made at each function are stored in that set, and the common effect is measured through union set theory, as shown in Figure 4. Figure 4 shows six different functions of a manufacturing process from A to F. Each function has a specific task and is used as input for the next function, and thus they are cross-functional and have subsequent impacts on each other. For example, if four changes are made to set $A$ (A1, A2, A3, A4) and $A 1, A 2$ of the changes influence $A$ and $B$, then $(A \cap B)=\{A 1, A 2\}$, so the interdependencies between $A$ and $B$ are $\{A 1, A 2\}$. Considering all the changes made to $A, B, C, D$ and $E$ are $(A \cup B \cup C \cup D \cup E)$, then ( $A \cap B \cap C \cap D \cap E$ ) is the set of interdependencies between all the units from $A$ to $E$ (Figure 4). The process of finding interdependencies through the KHB methodology is described in Figure 4. The governing principles of the cause and effect algorithm are discussed in Section 3.2.1.

\subsubsection{Cause and Effect Relationship (CER) between Functions}

The cause and effect relationship measure the effect of changes made to every function based on the production line data. In Figure 5, we can see the relationship between A and B. The common change that affects the production line between $A$ and $B$ is $\{3\}$, which defines $A \cap B=\{3\}$, and $A \cap C$ is $\{1,14\}$, as the common values between $A$ and $C$ are 1 and 14. Each of these numbers represents an interdependency for a specific change in functions.

\section{Set of all changes made $M=\{$ AUBUCUDUEUF $\}$}
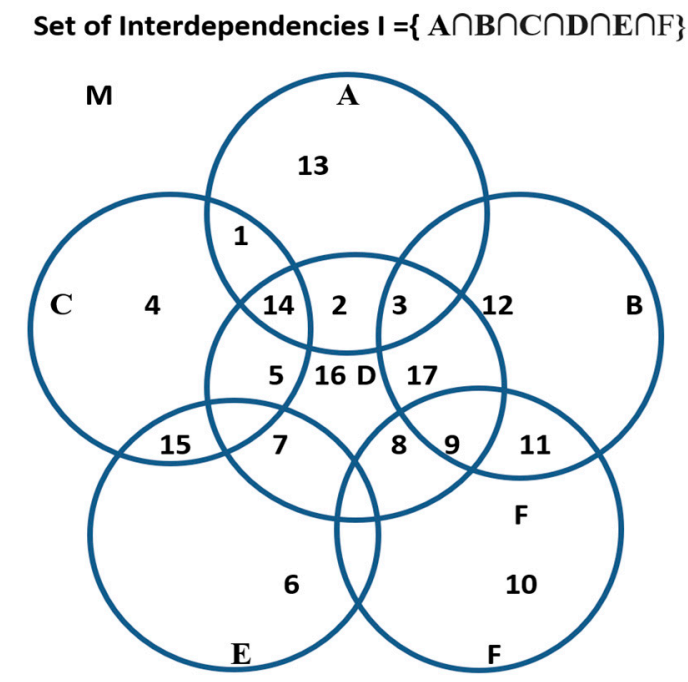

Figure 5. Cause and effect relationship (CER) between steps.

At the end of the process, there is a dataset $\{A \cup B \cup C \cup D \cup E \cup F\}$ that provides the set of all changes made in the re-engineering process, and $\{\mathrm{A} \cap \mathrm{B} \cap \mathrm{C} \cap \mathrm{D} \cap \mathrm{E} \cap \mathrm{F}\}$ provides the value for the cross-functional effect. This set represents the change that will affect the entire manufacturing process or the interdependencies between two functions (workstations). This relationship can filter the data, which will have a positive effect on the production line and feed the filtered data for the next cycle. The perimeters for the filtration process can be changed based on the objectives of the re-engineering process. For example, implementing changes in a specific function may impact the production of the subsequent or entire production process. The effect of those changes can be measured by finding out the interdependencies through the cause and effect relationship. If a change represented by $\{14\}$ is made to D (Figure 5), it will affect functions $A$ and $C$, as this is a common parameter and crosses the 
function between $\mathrm{A}, \mathrm{C}$ and $\mathrm{D}$. This effect can be measured using the relationship between $\mathrm{A}, \mathrm{C}$ and $\mathrm{D}$ $\{A \cap C \cap D\}$.

\subsection{Description of KHB Methodology}

KHB methodology consists of DDPR and a CEA. KHB methodology incorporates process interdependenceis along with DDPR for better output and a lesser percentage of failure. The methodology is shown in Figure 6 and starts with process mapping and gathering quantifiable (structured) data for DDPR (data driven process re-engineering), as described in Section 3.1. The re-engineering phase is the process where the interdependencies are identified through the cause and effect algorithm, as described in Section 3.2. In the manufacturing process, the interdependencies are sequential and reciprocal. The proposed approach identifies the process interdependencies from the data and uses them as decision-making tools for implementing the required changes. Data-driven process re-engineering identifies data as a new approach to process re-engineering and optimization. It uses a CEA to identify the interdependencies and decision-making tools to optimize performance and production. KHB methodology identifies the interdependencies through data analysis through a CEA.

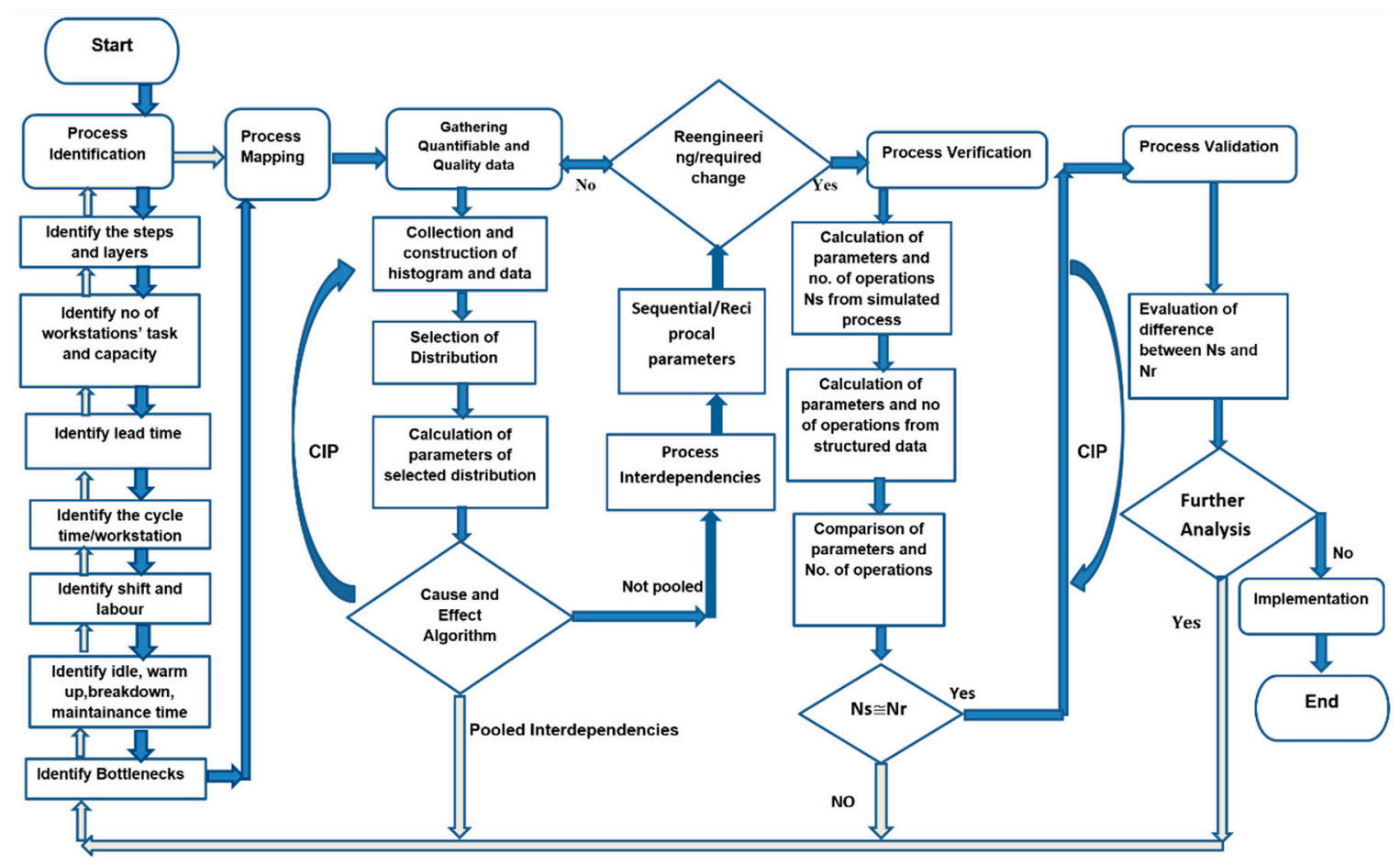

Figure 6. Proposed Khan-Hassan-Butt (KHB) methodology.

The re-engineering phase identifies the required changes for process development and implements those changes through simulation using the WITNESS Horizon 22 simulation package. Witness Horizon is a simulation package developed by the Lanner group, UK, and it is capable of simulating manufacturing processes. Figure 6 shows the re-engineering phases, identifying the sequential and reciprocal parameters of the functions through a CEA and deciding whether it requires any further data or can proceed to the next stage for verification. The verification process is described in Section 3.1.3 (DDPR). Once the verification is complete, the next stage starts with validation for implementation.

The KHB method shown in Figure 6 is a continuous improvement process. The process finds out the interdependencies between each change made, and a decision is made based on that. The methodology uses a CEA to analyze the PI using production line data and analyze the impact using simulations. This method was implemented in a case study (Section 4) to increase the production numbers and compare it to our previous work [10] to demonstrate its effectiveness. The KHB method uses structured 
manufacturing data to identify and eliminate interdependencies and transform them into smart structured data (SSD). In the process of filtering the interdependencies, it transforms the SD into SSD and simultaneously reduces the chances of failure in PR implementation. In process re-engineering approaches, the main reasons for failure are a lack of information between cross-functions, issues that arise between cross-functions, a lack of process knowledge and inappropriate methods. The KHB methodology identifies the cross-functional issues by analyzing the process interdependencies and using them as tools and techniques to choose appropriate methods to increase the efficiency of the process and decrease the chances of failure. The transformation of structured data (SD) into smart structured data (SSD) refers to filtering the parameters of the cross- and interdependent functions in a process that can be used as a decision-making tool for process optimization.

\section{Case Study}

The KHB methodology was implemented for a valve manufacturing process, as shown in Figure 7. The production line was optimized in our previous work using the data-driven process re-engineering approach, and the output was 421 [10]. As a process toward further development, the CEA was integrated with DDPR to analyze the PI as a decision-making tool. The production line was mapped using a Witness Horizon 22 simulation package following the methodology described in Section 3. The KHB methodology investigates structured data from the production line and filters the cause of the effect of different parameters that affect the production output. It was developed as a new approach to process re-engineering that identifies problems in a production line through a CEA rather than through analyzing a huge stream of production line data. It identifies the PI of each unit, which is used as a decision-making tool to optimize the process. It can be used to identify problems in the production line and filtration process to transform structured data into smart structured data.

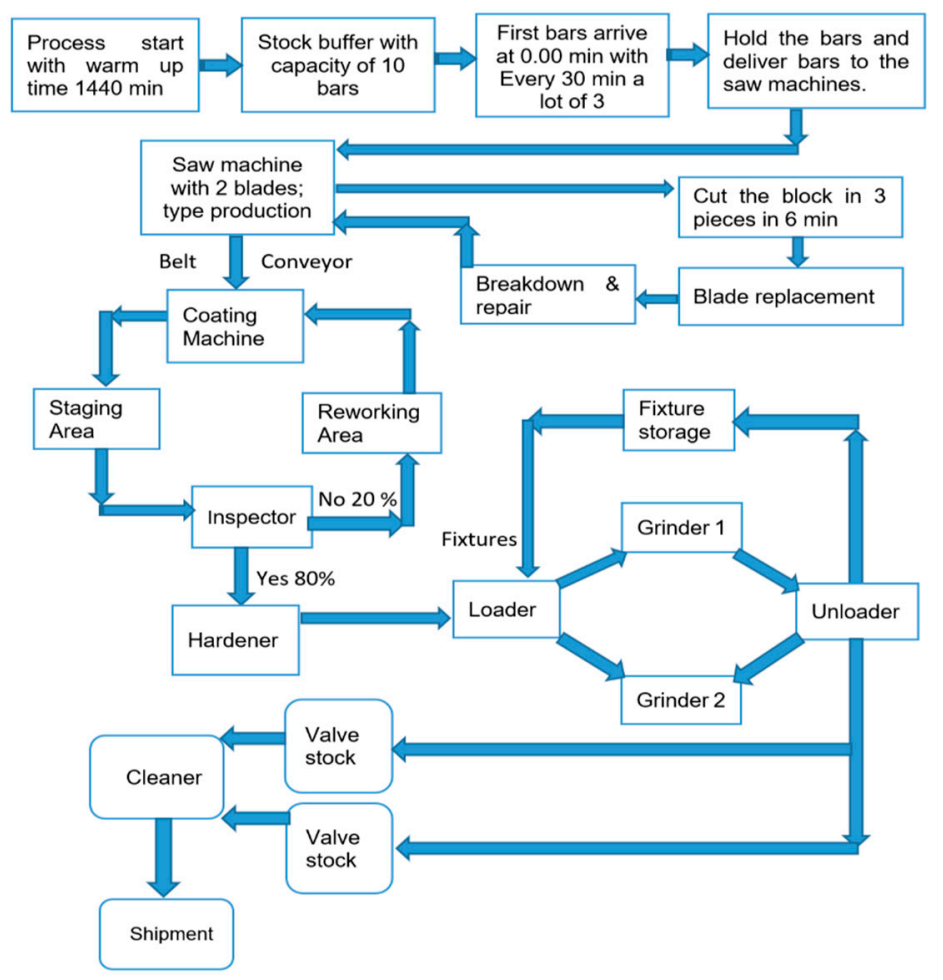

Figure 7. Data-driven process identification model [20].

The valve manufacturing process is shown in Figure 7. Sections 4.1-4.4 will discuss the case study: Section 4.4 will incorporate the data-driven process re-engineering approach [10], and Section 4.5 will show the combinational implementation of the KHB method. 


\subsection{Process Identification}

The manufacturing process has six different units, from the stock of raw materials to shipment. From the stocking of raw materials to the shipment of the valve, the process was identified through operations, procedures and data, and the units are as follows:

- Stock unit;

- Sawing and coating unit;

- Inspection and reworking unit;

- Hardening, loading and unloading;

- Stock and cleaning;

- Shipment.

The valve manufacturing process starts with stock buffer with a warmup time of $1440 \mathrm{~min}$, and it can hold 10 bars: the saw machine receives the bars from here and cuts them into three pieces and sends them to the coating machine.

The bars are coated and sent to the inspection area. The process has a high rejection rate of $20 \%$. The bars are sent to the reworking area with the priority of being recoated, and the rest of the $80 \%$ go through a hardening process to a loader. The loader loads a fixture from the fixture store and four bars from the hardener and feeds them to the grinder. The grinder presses the bars to make valves and delivers them to the unloader. The unloader sends the fixtures back to the fixture store and sends the valves back to the valve stocking area and subsequently the cleaner. The cleaner cleans the valves, packs them and delivers them for shipment.

\subsection{Mapping and Analysis of the Process}

The process was mapped using the Witness Horizon 22 simulation package. The production line has a warm-up time of 1440 min with 4500 working minutes in a week, and thus the run-time used in the simulation was $5940 \mathrm{~min}$. With the current specifications, the production line produced 120-160 valves within the given time span, as shown in Figures 8 and 9.

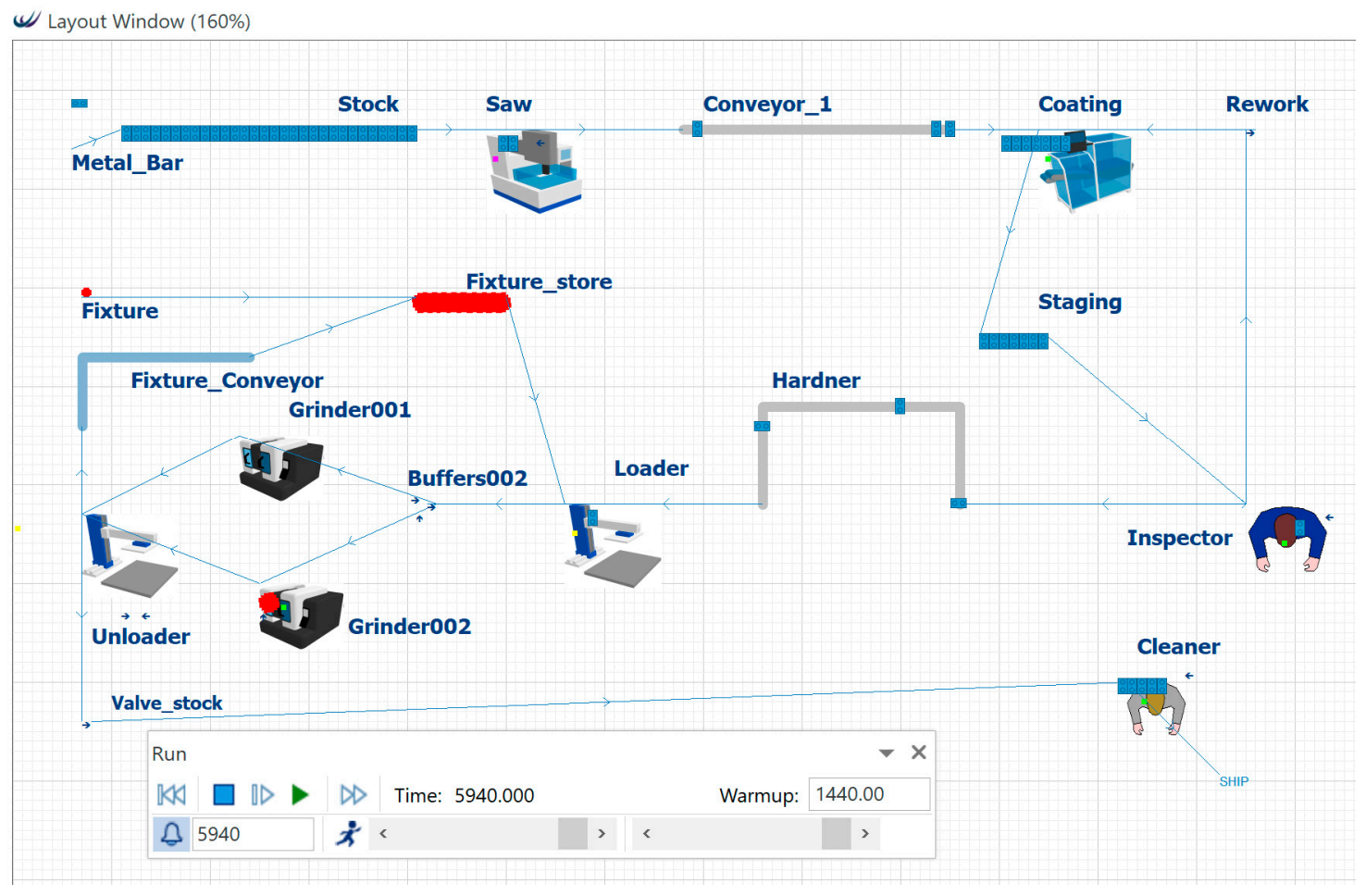

Figure 8. Valve manufacturing process mapping. 
Witness

Part Statistics Report by On Shift Time

\begin{tabular}{|c|r|r|r|r|r|r|r|r|r|}
\hline Name & No. Entered & No. Shipped & No. Scrapped & No. Assemble & No. Rejected & W.I.P. & Avg W.I.P. & Avg Time & Sigma Rating \\
\hline BAR & 326 & 141 & 0 & 136 & 13454 & 49 & 49.57 & 684.19 & 6.00 \\
\hline FIXTURE & 44 & 0 & 0 & 34 & 0 & 10 & 10.00 & 1022.73 & 6.00 \\
\hline
\end{tabular}

Figure 9. Process output for ACME valve manufacturing.

Figure 8 shows the mapped process of the valve manufacturing process in the Witness Horizon 22 simulation package. The process was mapped using the process identification described in Section 4.1. Process mapping represents the existing process of a system and thus uses the exact data from the process and requires verification to identify whether the mapped process has a similar operation and output or not compared to the actual process. The verification and validation of the mapped process are described in Section 4.3.

Figure 9 shows that the number of bars shipped was 141, which was the output of the system. Figure 10 represents the machine statistics of the valve manufacturing process. It shows that the busiest part of the process was the inspection and cleaning area, with a busy $\%$ of $80.95 \%$ and $47.04 \%$, respectively. In the process, the blockage times for the saw machine and the coating machine were $91.29 \%$ and $54.28 \%$, respectively. The process has a set-up time for the cleaner, saw and coating machine. From the busy \%, the inspection area was determined to be the bottleneck in the process, with the highest busy percentage.

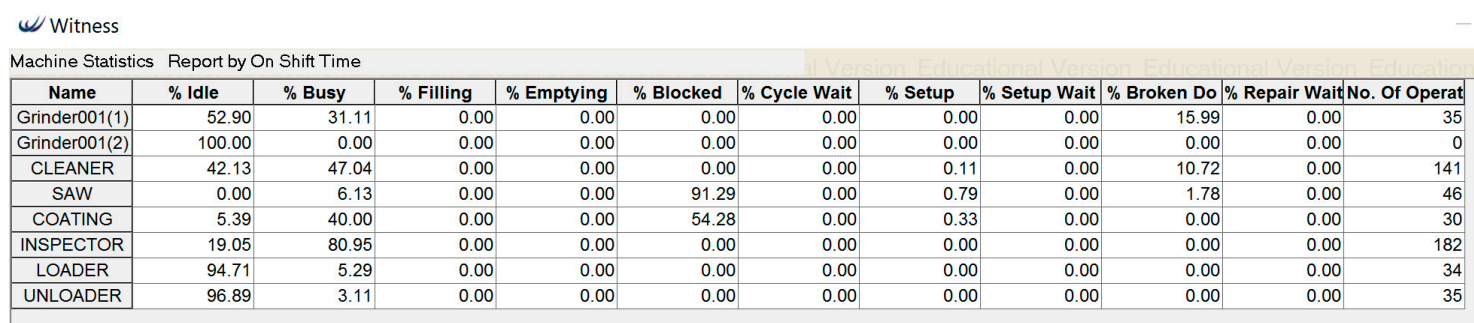

Figure 10. Machine statistics on shift times.

Figure 11 represents the machine statistics for the blockage, setup, busy percentage and breakdown times. Figures 10 and 11 show that the saw machine and the unloader were busy for the least amount of time.

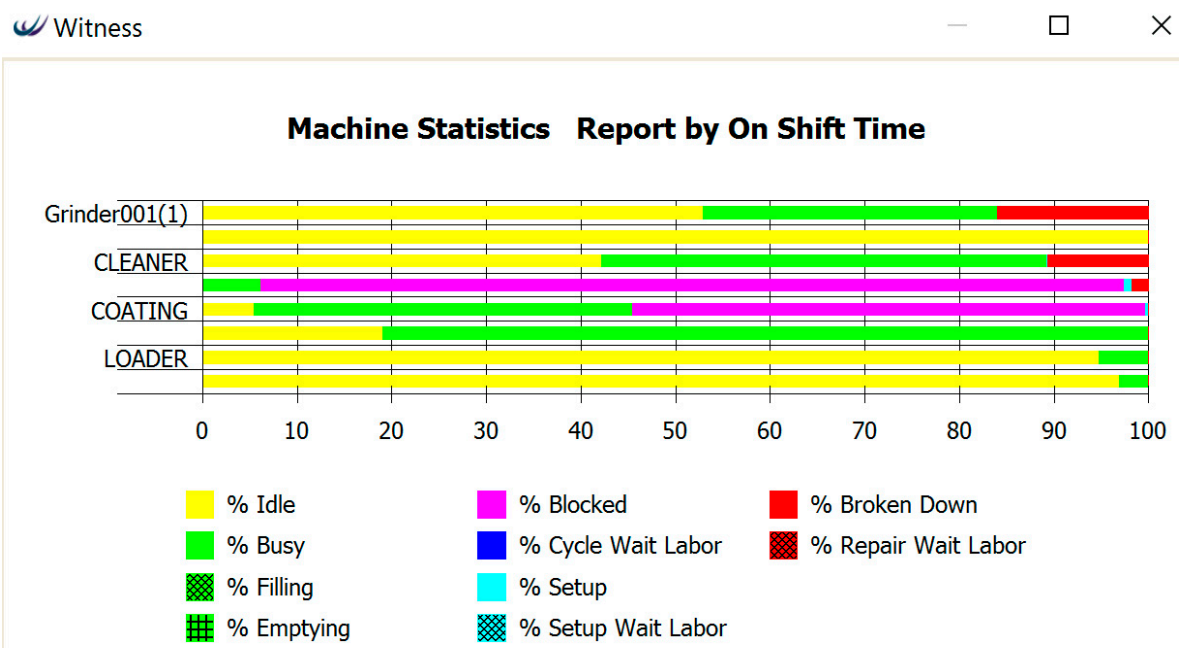

Figure 11. Chart statistics on shift time. 


\subsection{Process Verification}

The process can be simply verified by analyzing the flow and the output of the simulation (141) compared to the actual experimental data, which showed a range between 120 and 160 . The output will be the same in the simulation given fixed resources. However, without using any resources and only based on the shift time, the output may vary, but in this case, we used a fixed set-up, shift time, set-up time and breakdown time, so the output was the same for each run. The simulated values compared to the actual values were as follows:

- $\quad$ The total output $=120-160$, with an average value of 140;

- $\quad$ The total output of simulation $=141 \cong 140$.

The process mapped in Section 4.2 had different stages from the sawing area to the shipment. For the validation of the process, the saw machine data are described below:

Here, $B T s=$ busy time for the saw machine;

$R=$ process run time;

CTs = cycle time for saw machine.

Then, from Figure 10 we can see the following:

$B T s=6.13 \%$;

$R=4500 \mathrm{~min} ;$

$C T s=6 \mathrm{~min}$.

Then, the number of operations of the saw machine was the following:

$$
N s=\frac{B T s \times R}{C T s}
$$

or

$$
N s=\frac{0.0613 \times 4500}{6}
$$

or

$$
N s=45.975 \simeq 46 .
$$

In Figure 10, we can see the number of operations for the saw machine was 46, which was equivalent to the calculated value from the simulation data.

The coating machine data are the following:

$B T c=$ busy time for the saw machine;

$R=$ process run time;

$C T c=$ cycle time for the saw machine.

From Figures 8 and 10, we can see the following:

$B T c=40 \%$;

$R=4500 \mathrm{~min} ;$

$C T s=60 \mathrm{~min}$.

Then, the number of operations of the coating machine was

$$
N c=\frac{B T c \times R}{C T c}
$$

or

$$
N c=\frac{0.4 \times 4500}{60}
$$

or

$$
N c=30 .
$$

The calculated values for the coating machine's number of operations were equivalent to the data table in Figure 10. Therefore, it could be verified that the simulated process represented the actual process in terms of the number of operations completed by each function. 


\subsection{Re-Engineering Phase through Data-Driven Process Re-Engineering}

In the data-driven process re-engineering and optimization part, the data were considered for the identification of the bottleneck. The changes were made based on Table 1 . The optimization had an output of 421 that came at a cost of $£ 97,500$ [10]. The output and the simulation are shown in Figures 12-14. We aimed to increase the output based on the KHB method while keeping the budget the same, at $£ 97,500$.

Table 1. Changes for process optimization.

\begin{tabular}{ccc}
\hline Components & Existing Model & Modified Model \\
\hline Stock capability & 30 metal bars & 100 metal bars \\
Saw machine & Cycle time $=6 \mathrm{~min}$ & Cycle time $=6$ min \\
Coating machine & Cycle time $=60$ min, batch size $=6$ & Cycle time $=47.5$, batch size $=7$ \\
Inspection area & Inspector $=1$, cycle time $=0.1 \mathrm{~min}$ & Inspectors $=3$, cycle time $=0.1 \mathrm{~min}$ \\
Cleaner & Operator $=1$, cycle time $=0.1 \mathrm{~min}$ & Operators $=2$, cycle time $=0.1 \mathrm{~min}$ \\
Total output & 140 & 421 \\
Total resources spent & & $£ 97,500$ \\
\hline
\end{tabular}

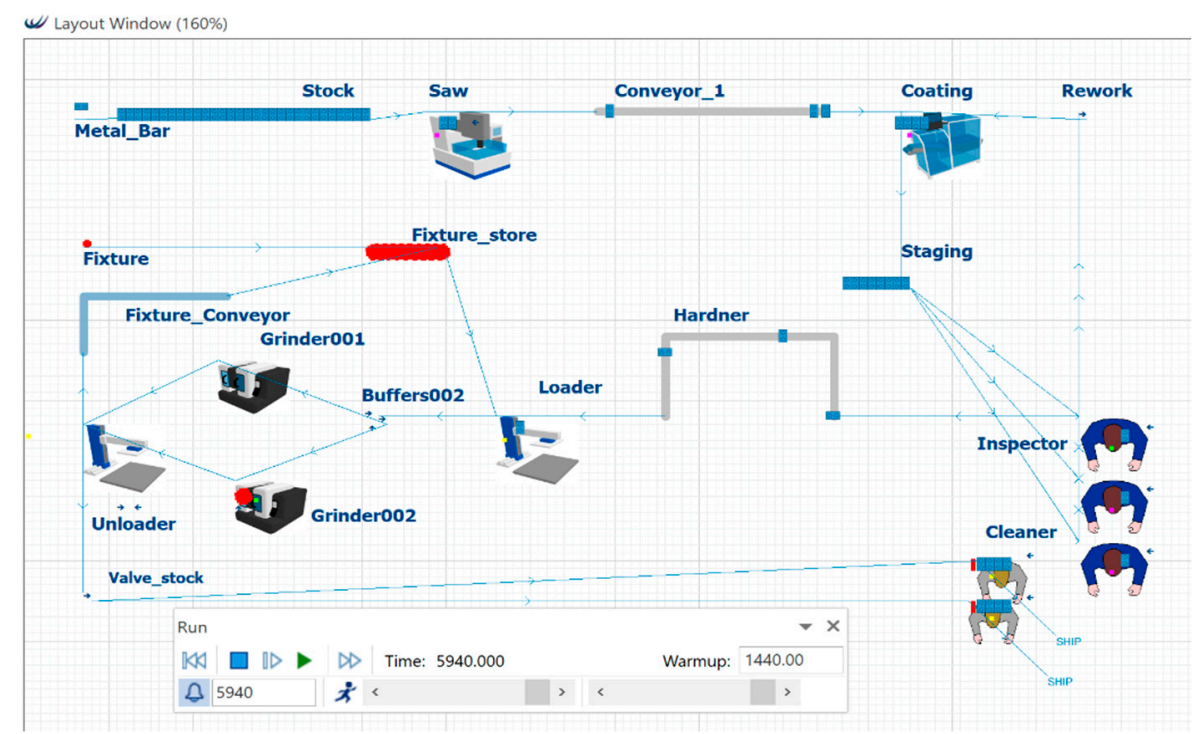

Figure 12. Re-engineered and optimized process for ACME valve manufacturing process using data-driven process re-engineering.

Witness
Part Statistics
\begin{tabular}{|c|r|r|r|r|r|r|r|r|r|}
\hline Name & No. Entered by On Shift Time & No. Shipped & No. Scrapped & No. Assemble & No. Rejected & W.I.P. & Avg W.I.P. & Avg Time & Sigma Rating \\
\hline BAR & 898 & 421 & 0 & 416 & 13361 & 61 & 65.74 & 329.46 & 6.00 \\
\hline FIXTURE & 114 & 0 & 0 & 104 & 0 & 10 & 10.00 & 394.74 & 6.00 \\
\hline
\end{tabular}

Figure 13. Part statistics on shift times in the re-engineered and optimized processes.

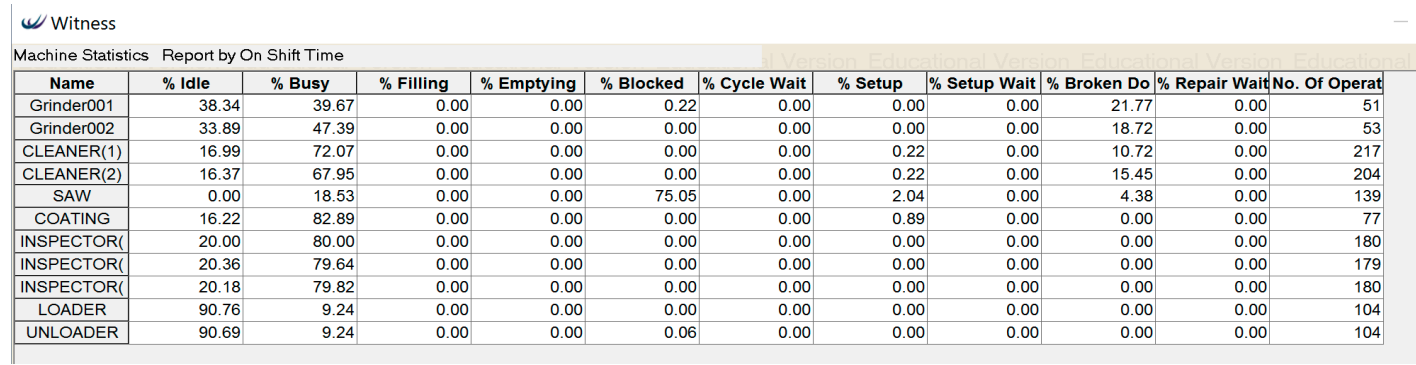

Figure 14. Machine statistics run on shift times. 
Figure 12 represents the optimized model of the valve manufacturing process, where certain changes were made based on the bottleneck, according to Table 1 . The optimized model had a similar runtime of $4500 \mathrm{~min}$ with $1440 \mathrm{~min}$ of warm-up time.

In the model, the bottleneck was the inspection area, and resources were added to reduce the cycle time, which increased the number of operations to 421 (Figure 13). The cycle times for the coating machine were balanced to maintain productabilty with the saw machine.

Figure 14 shows the machine statistics of the optimized model. If we compare the data from Figures 10 and 14, we can see changes in the busy percentage for all the machines. In Figure 14, the block \% of the saw machine was reduced to $75.05 \%$, and the coating machine was down to $0.00 \%$, while the number of operations increased to 139 and 77 consequently.

\subsection{Re-Engineering and Optimization Based on KHB Methodology}

It should be noted that only two machines were analyzed using the KHB methodology to demonstrate its effectiveness. Better output could be obtained by undertaking the same steps with other machines as well. Tables 3-6 and Equations (5)-(8) show the interdependencies between the saw and coating machines in changing the cycle time, number of operations, and the block \%. Increasing or decreasing the cycle time of the saw machine affected the number of operations and the block \%, while increasing or decreasing the cycle time of the coating machine affected the number of operations only.

For the saw machine, decreasing the cycle time increased the block \% of both the saw and coating machines, so increasing or decreasing the cycle time would not be efficient in optimizing the production line. On the other hand, decreasing the cycle time of the coating machine would be very efficient, as the interdependency was the number of operations, and with decreasing cycle times, the number of operations would increase. The data for the variable cycle times of the production line are described in Table 2a,b. Table 2a shows the impact on the saw machine for changing the cycle time of both saw and coating machines whereas Table $2 \mathrm{~b}$ shows the impact on the coating machine for changing the cycle time of both saw and coating machines.

Table 2. (a) Impact on saw machine for changes made to saw and coating machine. (b) Impact on coating machine changes made to saw and coating machine

\begin{tabular}{|c|c|c|c|c|c|}
\hline \multirow{3}{*}{ Changes } & \multicolumn{3}{|c|}{ (a) } & & \\
\hline & $\begin{array}{c}\text { Saw } \\
\text { Machine (P) }\end{array}$ & & & & \\
\hline & & Idle \% & Busy \% & Nop & Block \% \\
\hline Cycle (saw) & No change & 0 & 6.13 & 46 & 91.29 \\
\hline Reduction in cycle time, c $(4,3)$ & & 0 & $\begin{array}{c}\mathrm{b} \\
(4.27,3.2)\end{array}$ & $\mathrm{N}(48,48)$ & BL $(94.1,95.64)$ \\
\hline Increase in cycle time, $C(12,8)$ & & 0 & $\begin{array}{c}\text { B } \\
(12.27,8.18)\end{array}$ & $\mathrm{n}(46,46)$ & bl $(83.72,89.62)$ \\
\hline Change & Coating $(Q)$ & & & & \\
\hline Cycle time for coating & No change & 0 & 6.13 & 46 & 91.29 \\
\hline Reduction in cycle time, c $(50,45)$ & & 0 & $\begin{array}{c}\text { B } \\
(6.53,6.93)\end{array}$ & $\mathrm{N}(49,52)$ & bl $(91.27,90.87)$ \\
\hline Increase in cycle time, $C(70,65)$ & & & $\begin{array}{c}\mathrm{b} \\
(5.73,5.87)\end{array}$ & n $(43,44)$ & BL $(91.93,91.56)$ \\
\hline
\end{tabular}


Table 2. Cont.

\begin{tabular}{|c|c|c|c|c|c|}
\hline \multicolumn{6}{|c|}{ (b) } \\
\hline Changes & $\begin{array}{c}\text { Coating } \\
\text { Machine }(Q)\end{array}$ & & & & $\begin{array}{l}\text { Total output } \\
\text { (TO) }\end{array}$ \\
\hline & Idle \% & Busy\% & Nop & Block\% & \\
\hline Cycle (saw) & 5.39 & 40 & 30 & 54.28 & 141 \\
\hline Reduction in cycle time, c $(4,3)$ & $\mathrm{i}(2.79,2.37)$ & B $(41.33,41.94)$ & $\mathrm{N}(31,31)$ & BL $(55.43,55.24)$ & $\mathrm{O}(146,145)$ \\
\hline Increase in cycle time, $C(12,8)$ & I $(6.90,5.45)$ & $\mathrm{b}(39.67,40)$ & $\mathrm{n}(29,30)$ & bl $(53.47,54.22)$ & o $(139,136)$ \\
\hline \multicolumn{6}{|l|}{ Change } \\
\hline Cycle time for coating & 5.39 & 40 & 30 & 54.28 & 141 \\
\hline Reduction in cycle time, c $(50,45)$ & I $(5.74,5.87)$ & $\mathrm{b}(35.68,34)$ & $\mathrm{N}(33,34)$ & BL $(58.25,59.8)$ & $\mathrm{O}(152,157)$ \\
\hline Increase in cycle time, $C(70,65)$ & $\mathrm{i}(5.02 .5 .13)$ & B $(44.87,42.23)$ & $\mathrm{n}(28), 30)$ & bl $(49.78,52.31)$ & o $(132,136)$ \\
\hline
\end{tabular}

\subsubsection{Measuring Interdependency in the Saw and Coating Machines}

Figure 15 and Tables 3-6 show the interdependencies between the saw and coating machines. To identify the interdependency of the process, the cycle times were decreased/increased, and the impact was measured for machine idle time, block \% and number of operations. Table 2 shows the consequent output when changing the cycle time in the simulation. A simulation was run with a run-time of $4500 \mathrm{~min}$ for each of the values of the cycle time. There was only one change made in each simulation to pinpoint the impact on the consecutive functions. In Table 2, we can see that with decreasing cycle times in the saw machine to 4 and 3, busy $\%$ decreased to $4.27 \%$ and $3.2 \%$, the number of operations increased to 48 and block \% increased to $94.1 \%$ and $95.64 \%$ for the saw machine. When the cycle time decreased to 4 and 3, the coating machine was affected, with a decrease in idle $\%$ to $2.79 \%$ and $2.37 \%$, an increase in busy $\%$ to $41.33 \%$ and $41.94 \%$, an increase in the number of operations to 31 , a block \% of $55.43 \%$ and $55.24 \%$ and a total process output of 146 and 145 . The data for increasing and decreasing cycle times for both the saw and coating machines and their consequent output are stored in Table 2. The interdependencies between the saw and coating machines for changing cycle times of the saw machine are described in Tables 3 and 4 and in Equations (5) and (6).
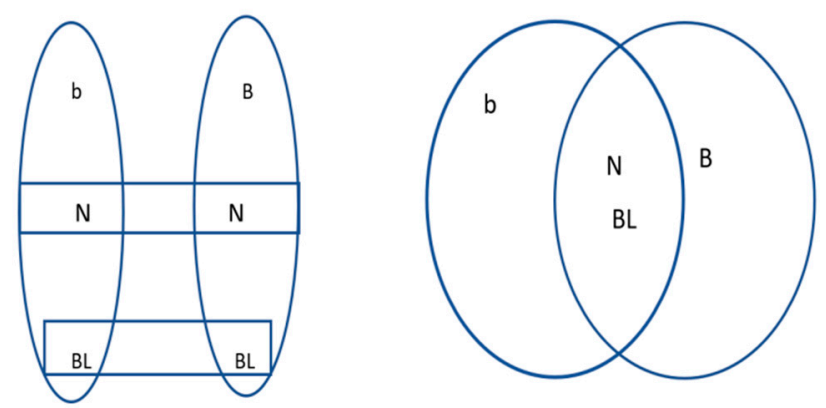

Figure 15. Interdependency between the saw and coating machines.

Table 3. Interdependencies for decreasing cycle times of the saw machine.

\begin{tabular}{cccc}
\hline Change & Busy \% & Nop & Block \% \\
\hline Saw machine & Decrease & Increase & Increase \\
Coating machine & Increase & Increase & Increase \\
\hline
\end{tabular}


Table 4. Interdependencies for increase in cycle time of saw machine.

\begin{tabular}{cccc}
\hline Change & Busy\% & Nop & Block\% \\
\hline Saw machine & Increase & Decrease & Decrease \\
Coating machine & Decrease & Decrease & Decrease \\
\hline
\end{tabular}

Table 5. Interdependencies for an increase in the cycle time of the coating machine.

\begin{tabular}{cccc}
\hline Change & Busy $\%$ & Nop & Block \% \\
\hline Coating & Increase & Decrease & Decrease \\
Saw & Decrease & Decrease & Increase \\
\hline
\end{tabular}

Table 6. Interdependencies for decreasing cycle times of the coating machine.

\begin{tabular}{cccc}
\hline Change & Busy \% & Nop & Block \% \\
\hline Coating & Decrease & Increase & Increase \\
Saw & Increase & Increase & Decrease \\
\hline
\end{tabular}

For decreases in the cycle time of the saw machine, the resulting output was as follows for both the saw and coating machines.

This resulted in an interdependency equation, as follows:

$$
P \cap Q=\{B L, N\}
$$

Figure 15 shows the effect on both the saw and coating machines for decreases in the cycle time of the saw machine. The changes had similar effects on the number of operations and block \%. With a cycle time decrease, both block \% and Nop increased. Therefore, it could be determined that decreases in the cycle time of the saw machine would have common interdependencies with the number of operations and block percentage.

Table 2 shows that increases in the cycle time of the saw machine affected both the saw and the coating machine. For a cycle time of 12 and 8, the saw machine's busy \% increased to $12.27 \%$ and $8.18 \%$, the number of operations remained the same, and block \% decreased to $83.72 \%$ and $89.62 \%$. The coating machine was affected, with a decrease in busy $\%$ to $39.67 \%$ and $40 \%$, the number of operations at 29 and 30 and block \% at $53.47 \%$ and $54.22 \%$, while total output decreased to 139 and 136 . Similar simulations were run for decreasing and increasing cycle times of the coating machine, and the consequent values are stored in Table 2. The resulting output for the coating machine is described in Tables 5 and 6 and in Equations (7) and (8).

For increasing the cycle time of the saw machine, the output was as follows.

This resulted in an interdependency equation as follows:

$$
P \cap Q=\{n, b l\} .
$$

\subsubsection{Measuring Interdependency for the Coating Machine}

To measure the interdependency of the coating machine relative to the saw machine, it was crucial to analyze the effect of increasing/decreasing cycle times of the coating machine. This effect is shown in Table 5.

This resulted in an interdependency equation for the coating and saw machine as follows:

$$
Q \cap P=\{n\}
$$

For decreases in the cycle time of the coating machine, the consequent output is shown in Table 6. 
This resulted in an interdependency equation as follows:

$$
Q \cap P=\{N\}
$$

To increase the efficiency of the process, it was required to decrease the block \% of the saw machine. In Section 4.5 and Figure 13, the optimized output was 421 [10]. The optimization was done based on process identification through data and through finding the bottleneck. In the proposed approach, the optimization was done considering both the bottleneck and the interdependency. Figure 15 and Tables 3-6 show the interdependency between the saw and coating machines (number of operations and block \%). Figure 10 shows simulation data on the existing process. In the existing process, the coating machine had a much higher cycle time compared to the saw machine. The interdependency showed that bringing any change to the cycle time of the coating machine affected the block $\%$ and number of operations. Figure 10 shows that the block \% of the saw machine was $91.29 \%$ and that the coating machine was at $54.28 \%$. To increase the efficiency according to the interdependency, we needed to decrease the block \%.

The blockage that was created on the saw machine was because of the capacity of the coating machine. As the coating machine had a higher cycle time, it could not process the same amount of parts produced by the saw machine. The valve manufacturing process has sequential interdependence, where the output of one unit is being used as the input for the following unit. Because of the differences in the number of operations performed by both machines, the saw machine would stop working after a certain number of operations when the difference between the number of operations exceeded the stocking capacity of the conveyor. To avoid this problem, a stock buffer was added to reduce that blockage between the saw and coating machines. Incorporating these aspects, the output increased to 504 compared to 421 (as calculated in our previous work [10]) with the same budget. The values used to optimize the model are described in Table 7. The bottleneck of the process was the inspection area, which was balanced using extra inspectors and cost the biggest amount. This showed an increase of approximately $20 \%$ in output by using the KHB methodology. It should be noted that only two machines (the saw and coating machines) were analyzed through the newly proposed method, and further analysis could lead to even higher output.

Table 7. Comparison of outputs.

\begin{tabular}{ccc}
\hline Components & Data-Driven Process Re-Engineering & KHB Methodology \\
\hline Stock & 30 metal bars & 100 metal bars \\
Saw machine & Cycle time $=6$ min & Cycle time $=6$ min \\
Coating machine & Cycle time $=47.5$ min, batch size $=7$ & Cycle time $=47.5$, batch size $=7$ \\
Inspection area & Inspectors $=3$, cycle time $=0.1 \mathrm{~min}$ & Inspectors $=3$, cycle time $=0.1 \mathrm{~min}$ \\
Cleaner & Operators $=2$, cycle time $=0.1 \mathrm{~min}$ & Operators $=2$, cycle time $=0.1 \mathrm{~min}$ \\
Total output & 421 & 504 \\
\hline
\end{tabular}

The optimized simulation model and data based on the interdependency are shown in Figures 16 and 17 , respectively. This result was $20 \%$ higher than our previous optimization based on DDPR [10].

The cycle time and batch size of the coating machine were compensated for and were changed to 47.5 and 7 to balance the interdependency between the saw and coating machines, which included the block \% and number of operations. Figure 18 shows that the block \% of the saw and coating machines was reduced to $70.93 \%$ and $0.00 \%$ from $91.29 \%$ and $54.28 \%$ in the existing process (see Figure 10 ). The number of operations went up to 167 and 92 from 46 and 30.

Figure 19 represents the machine statistics in terms of shift times of the optimized model. It shows that the saw machine had the highest amount of block \%, although it was reduced almost by $22 \%$ from the existing process. The block \% could be further reduced by decreasing the cycle time of the coating machine or by increasing the stock capability of the saw area. 


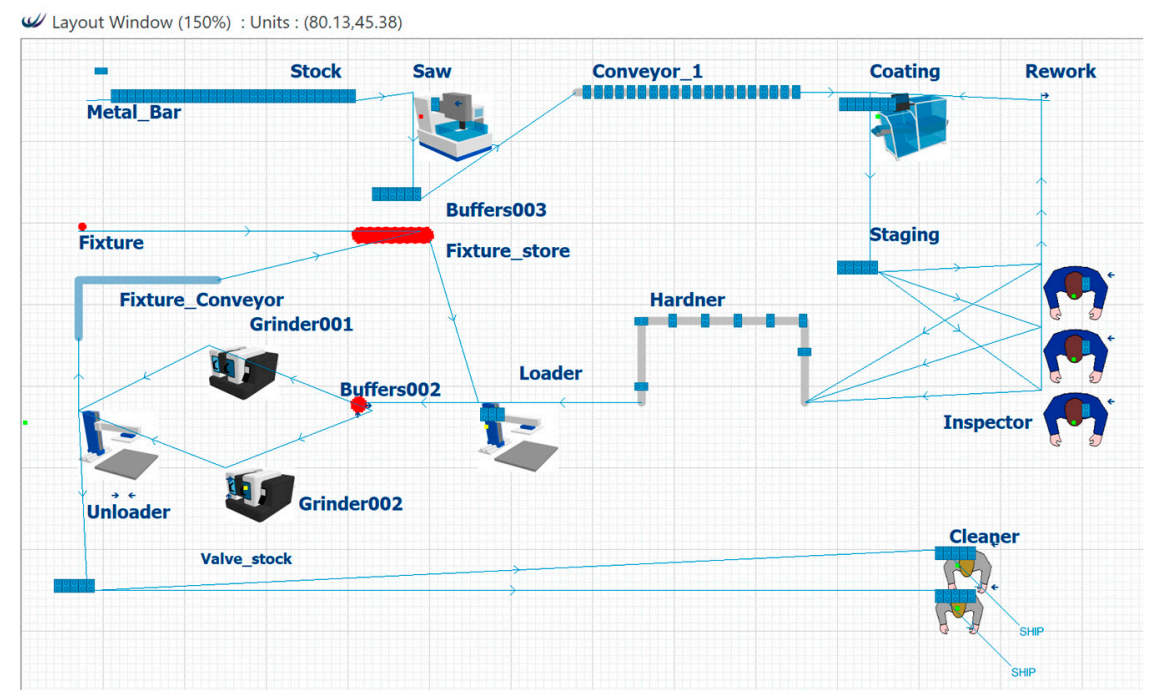

Figure 16. Re-engineering and optimization based on a generic model of change and effect.

Witness

Part Statistics Report by On Shift Time

\begin{tabular}{|c|r|r|r|r|r|r|r|r|r|}
\hline Name & No. Entered & No. Shipped & No. Scrapped & No. Assemble & No. Rejected & W.I.P. & Avg W.I.P. & Avg Time & Sigma Rating \\
\hline Metal_Bar & 1102 & 504 & 0 & 500 & 13332 & 98 & 98.36 & 401.66 & 6.00 \\
\hline Fixture & 135 & 0 & 0 & 125 & 0 & 10 & 10.00 & 333.33 & 6.00 \\
\hline
\end{tabular}

Figure 17. Part statistics of the optimized model.

Machine Statistics Report by On Shift Time

\begin{tabular}{|c|r|r|r|r|r|r|r|r|r|r|r|}
\hline Name & \% Idle & \% Busy & \% Filling & \% Emptying & \% Blocked & \% Cycle Wait & \% Setup & \% Setup Wait & \% Broken Do \% Repair Wait No. Of Operat \\
\hline Grinder001 & 26.50 & 47.67 & 0.00 & 0.00 & 0.94 & 0.00 & 0.00 & 0.00 \\
\hline Grinder002 & 22.60 & 56.89 & 0.00 & 0.00 & 0.05 & 0.00 & 0.00 & 0.00 & 24.89 \\
\hline Cleaner(1) & 3.07 & 85.88 & 0.00 & 0.00 & 0.00 & 0.00 & 0.33 & 0.00 & 10.47 \\
\hline Cleaner(2) & 2.48 & 81.73 & 0.00 & 0.00 & 0.00 & 0.00 & 0.33 & 0.00 & 15.45 \\
\hline Saw & 0.00 & 22.27 & 0.00 & 0.00 & 70.93 & 0.00 & 2.28 & 0.00 & 4.52 & 0.00 \\
\hline Coating & 2.31 & 96.58 & 0.00 & 0.00 & 0.00 & 0.00 & 1.11 & 0.00 & 0.00 \\
\hline Inspector(1) & 4.90 & 95.10 & 0.00 & 0.00 & 0.00 & 0.00 & 0.00 & 0.00 & 0.00 \\
\hline Inspector(2) & 5.02 & 94.98 & 0.00 & 0.00 & 0.00 & 0.00 & 0.00 & 0.00 & 0.00 \\
\hline Inspector(3) & 5.03 & 94.97 & 0.00 & 0.00 & 0.00 & 0.00 & 0.00 & 0.00 & 0.00 \\
\hline Loader & 88.89 & 11.11 & 0.00 & 0.00 & 0.00 & 0.00 & 0.00 & 0.00 & 0.00 \\
\hline Unloader & 83.51 & 11.20 & 0.00 & 0.00 & 5.29 & 0.00 & 0.00 & 0.00 & 0.00 \\
\hline
\end{tabular}

Figure 18. Part statistics supported by cause and effect re-engineering and optimization.

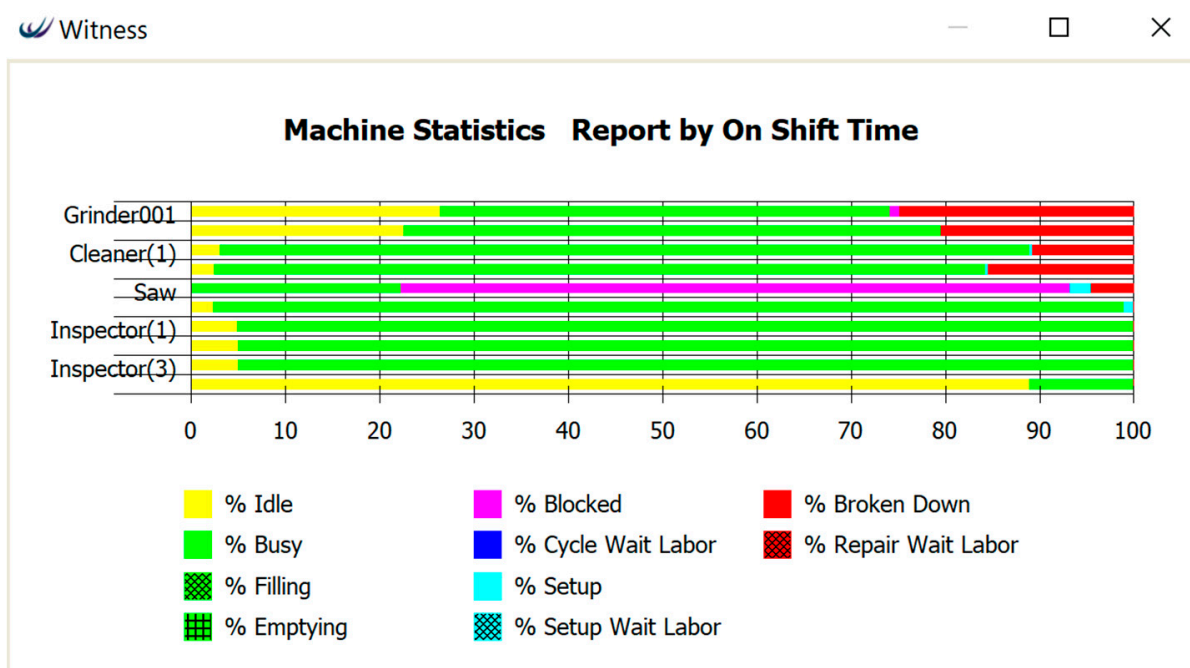

Figure 19. Machine statistics based on cause and effect re-engineering. 
Figure 17 shows that the optimized cycle time for the coating machine was 47.5 , while the data from the saw machine and the coating machine were considered. It took a certain amount of resources to reduce the cycle time from 60 to 47.5 and provide a maximum output of 504 . The production of the coating machine depended on the production of the saw machine. Two different scenarios were considered based on process identification:

a. If the increase in the number of operations affected the coating machine production;

b. If the increase in resources in both the saw and coating machines affected the output.

The production of the coating machine was affected if the output was not equivalent to the production of the saw machine, as the sawed bar had to wait on the conveyor and the saw machine would be blocked until the coating machine completed the coating of a similar number of bars. Considering the bottleneck and the existing model, the simulation showed the coating and the inspector had the highest busy percentage. However, because of the relationship between the saw machine and the coating machine after a certain number of operations, the bars queued between the saw and the coating machine. If the cycle time of the coating machine was decreased or the batch size was increased, this problem could be solved up to a certain time. However, if the opposite happened (for example, if the number of operations of the saw machine was less than the coating machine), it would not be efficient to increase or decrease the cycle time, as it would not add any extra value to the output. Considering both scenarios, we needed to compensate for the cycle time between the saw machine and coating machine and added an extra buffer in between the conveyor and the saw machine to eliminate the interdependencies to decrease the block \%. The CEA considered the effects of the changes made to the cycle time or batch size and set up a bridge between the two steps. Therefore, if the total output of the saw machine $N(P) \geq$ the total number of outputs of the coating machine $N(Q)$ or vice versa, the output from $P$ would wait in the buffer, which decreased the blockage from the saw machine. A similar output could be achieved by decreasing the cycle time on the coating machine by $20 \%$ and increasing the batch size from 6 to 7 . In that case, the inspection area was affected, which increased the production costs. In this manufacturing process, adding substeps between the saw machine and the conveyor increased the efficiency of the process and reduced the implementation cost by about $15 \%$. This clearly showed the effectiveness of the KHB method in optimizing a process.

\section{Conclusions}

The exploding amount of data produced by industries is a big challenge and thus requires a filtration process to transform data into smart data to understand the characteristics of manufacturing processes. The process re-engineering technique has long been used for the optimization of manufacturing processes. The difference between the conventional process re-engineering technique and the cause and effect process re-engineering technique is an investigation of the manufacturing process by analyzing the structured data and verifying fitness for implementation. It identifies the unproductive steps that increase the lead time of a product and optimizes the process by measuring the optimal effects made by a certain change and transforms the structured data into smart data. A new methodology, termed the KHB method, was presented to analyze interdependencies, and it is a combination of a cause and effect algorithm and data-driven process re-engineering. In the presented case study, the output of the manufacturing process was increased by $20 \%$ using the KHB method. The cause and effect re-engineering approach integrated the structured data into the process re-engineering technique as a methodology and filtered the data. In terms of limitations, the KHB method is compatible only with structured data. The methodology described in this work made use of structured data from a production line and experiments using the WITNESS Horizon 22 simulation package. The process can be used for unstructured data and semistructured data as well, which will require further research to identify the effects of external factors such as market conditions, challenges and customer satisfaction. Unstructured and semi-structured data will be useful in predicting the demand and nature of the market, while smart structured data will be more useful in getting optimal production based on 
that demand. In the case study presented in this paper, the resulting output based on the KHB method showed a $20 \%$ increase compared to our previous work. However, this increase was a result of interdependency measurements of only two units (the saw and coating machines). Further investigation to find out the interdependencies of the entire process can provide better output and accuracy. The process can be developed based on PI by establishing an equation that will provide numerical values for the required number of operations to be performed and the changes in cycle time, busy $\%$ and block \% to be achieved. However, further investigation is required to establish an equation that will provide numerical values for different parameters of process interdependencies, which is a topic for our future research.

Author Contributions: M.A.A.K and J.B. conceptualized the idea, defined the methodology and wrote the first draft of the manuscript; M.A.A.K., A.S. and M.N.A. ran the simulations, J.B., H.S. and H.M. worked on manuscript review and editing.

Funding: This research received no external funding.

Conflicts of Interest: The authors declare no conflict of interest.

\section{Nomenclature}

$\begin{array}{ll}\text { AM } & \text { Agile manufacturing } \\ \text { BPR } & \text { Business process re-engineering } \\ \text { CEA } & \text { Cause and effect algorithm } \\ \text { CER } & \text { Cause and effect relationship } \\ \text { CPS } & \text { Cyber physical system } \\ \text { DDPR } & \text { Data-driven process re-engineering } \\ \text { IOT } & \text { Internet of things } \\ \text { LM } & \text { Lean manufacturing } \\ \text { KHB } & \text { Khan-Hassan-Butt } \\ \text { MPR } & \text { Manufacturing process re-engineering } \\ \text { MPS } & \text { Master production schedule } \\ \text { MRP } & \text { Material requirements planning } \\ \text { PI } & \text { Process interdependencies } \\ \text { POF } & \text { Process optimization framework } \\ \text { PR } & \text { Process re-engineering } \\ \text { SD } & \text { Structured data } \\ \text { SSD } & \text { Smart structured data } \\ \text { MP } & \text { Manufacturing process }\end{array}$

\section{References}

1. Chassiakos, A.; Karatzas, S.; Farmakis, P. BIM and Lean-Business Process Reengineering for Energy Management Optimization of Existing Building Stock. In Advances in Informatics and Computing in Civil and Construction Engineering; Springer: Cham, Switzerland, 2019; pp. 711-718.

2. Zhang, Q.; Cao, M. Business process reengineering for flexibility and innovation in manufacturing. Ind. Manag. Data Syst. 2002, 102, 146-152. [CrossRef]

3. Khan, M.A.; Mebrahtu, H.; Shirvani, H.; Butt, J. Manufacturing optimization based on agile manufacturing and big data. In Advances in Manufacturing Technology XXXI; IOS Press: London, UK, 2017; pp. 345-351.

4. Moyne, J.; Iskandar, J. Big data analytics for smart manufacturing: Case studies in semiconductor manufacturing. Processes 2017, 5, 39. [CrossRef]

5. Davis, J.; Edgar, T.; Porter, J.; Bernaden, J.; Sarli, M. Smart manufacturing, manufacturing intelligence and demand-dynamic performance. Comput. Chem. Eng. 2012, 47, 145-156. [CrossRef]

6. Lee, J.; Bagheri, B.; Kao, H.A. A cyber-Physical systems architecture for industry 4.0-Based manufacturing systems. Manuf. Lett. 2015, 3, 18-23. [CrossRef] 
7. Wang, S.; Wan, J.; Zhang, D.; Li, D.; Zhang, C. Towards smart factory for industry 4.0: A self-Organized multi-Agent system with big data-Based feedback and coordination. Comput. Netw. 2016, 101, 158-168. [CrossRef]

8. Abdellatif, M.; Farhan, M.S.; Shehata, N.S. Overcoming business process reengineering obstacles using ontology-Based knowledge map methodology. Future Comput. Inform. J. 2018, 3, 7-28. [CrossRef]

9. Rao, L.; Mansingh, G.; Osei-Bryson, K.M. Building ontology-Based knowledge maps to assist business process re-Engineering. Decis. Support Syst. 2012, 52, 577-589. [CrossRef]

10. Khan, M.; Butt, J.; Mebrahtu, H.; Shirvani, H.; Alam, M. Data-Driven Process Reengineering and Optimization Using a Simulation and Verification Technique. Designs 2018, 2, 42. [CrossRef]

11. Zarvić, N.; Stolze, C.; Boehm, M.; Thomas, O. Dependency-Based IT Governance practices in inter organizational collaborations: A graph-Driven elaboration. Int. J. Inf. Manag. 2012, 32, 541-549. [CrossRef]

12. Wang, H.; Gong, Q.; Wang, S. Information processing structures and decision-Making delays in MRP and JIT. Int. J. Prod. Econ. 2017, 188, 41-49. [CrossRef]

13. Butt, J.; Mebrahtu, H.; Shirvani, H. Peel and tensile test investigation of aluminium 1050 foil parts made with a new additive manufacturing process. Int. J. Rapid Manuf. 2015, 5, 95-115. [CrossRef]

14. Butt, J.; Mebrahtu, H.; Shirvani, H. Thermo-Mechanical analysis of dissimilar al/cu foil single lap joints made by composite metal foil manufacturing. World Acad. Sci. Eng. Technol. Int. J. Mech. Aerospa. Ind. Mech. Manuf. Eng. 2015, 10, 41-46.

15. Butt, J.; Shirvani, H. Experimental analysis of metal/plastic composites made by a new hybrid method. Addit. Manuf. 2018, 22, 216-222. [CrossRef]

16. Butt, J.; Shirvani, H. Additive, Subtractive, and Hybrid Manufacturing Processes. In Advances in Manufacturing and Processing of Materials and Structures; CRC Press: Boca Raton, FL, USA, 2018; pp. 187-218.

17. Rosemary, R.; Fullertona, F. Management accounting and control practices in a lean manufacturing environment. Account. Organ. Soc. 2013, 38, 50-71.

18. Dev, C.A.G.; Kumar, V.S. Analysis on critical success factors for agile manufacturing evaluation in original equipment manufacturing industry-An AHP approach. Chin. J. Mech. Eng. 2016, 29, 880-888.

19. Dubey, R.; Gunasekaran, A.; Chakrabarty, A. World-class sustainable manufacturing: framework and a performance measurement system. Int. J. Prod. Res. 2015, 53, 5207-5223. [CrossRef]

20. Kennedyb, F.A. Lean manufacturing and firm performance: The incremental contribution of lean management accounting practices. J. Oper. Manag. 2014, 32, 414-428.

21. Davenport, T.H.; Short, J.E. The new industrial engineering: Information technology and business process redesign. Solan. Manag. Rev. 1990, 31, 11-27.

22. Michael, H.; James, C. Reengineering the Corporation: A Manifesto for Business Revolution; HarperCollins: New York, NY, USA, 1993.

23. Al-Mashari, M.; Zahir, I.; Mohamed, Z. Business process reengineering: A survey of international experience. Bus. Process. Manag. J. 2001, 7, 437-455. [CrossRef]

24. Hussein, B.; Hammoud, M.; Bazzi, H.; Haj-Ali, A. PRISM-Process reengineering integrated spiral model: An agile approach to business process reengineering (BPR). Int. J. Bus. Manag. 2014, 9, 134. [CrossRef]

25. Abdolvand, N.; Albadvi, A.; Ferdowsi, Z. Assessing readiness for business process reengineering. Bus. Process Manag. J. 2008, 14, 497-511. [CrossRef]

26. Herzog, N.V.; Polajnar, A.; Tonchia, S. Development and validation of business process reengineering (BPR) variables: a survey research in Slovenian companies. Int. J. Prod. Res. 2007, 45, 5811-5834. [CrossRef]

27. McAdam, R.; O'Hare, C. An improved BPR approach for offline enabling processes: A case study on a maintaining process within the chemical industry. Bus. Process Manag. J. 1998, 4, 226-240. [CrossRef]

28. Kettler, N.; Soffer, P.; Hadar, I. Towards a Knowledge Base of Business Process Redesign: Forming the Structure. In Enterprise, Business-Process and Information Systems Modeling; Springer: Cham, Switzerland, 2019; pp. 3-18.

29. Belmiro, T.R.; Gardiner, P.D.; Simmons, J.E.; Rentes, A.F. Are BPR practitioners really addressing business processes? Int. J. Op. Prod. Manag. 2000, 20, 1183-1203. [CrossRef]

30. Qu, Y.; Ming, X.; Ni, Y.; Li, X.; Liu, Z.; Zhang, X.; Xie, L. An integrated framework of enterprise information systems in smart manufacturing system via business process reengineering. Proc. Inst. Mech. Eng. Part B J. Eng. Manuf. 2018, 0954405418816846. [CrossRef] 
31. Lu, Y. Industry 4.0: A survey on technologies, applications and open research issues. J. Ind. Inf. Integr. 2017, 6, 1-10. [CrossRef]

32. Chen, B.; Wan, J.; Shu, L.; Li, P.; Mukherjee, M.; Yin, B. Smart factory of industry 4.0: Key technologies, application case, and challenges. IEEE Access 2018, 6, 6505-6519. [CrossRef]

33. Lee, J.; Lapira, E.; Bagheri, B.; Kao, H.A. Recent advances and trends in predictive manufacturing systems in big data environment. Manuf. Lett. 2013, 1, 38-41. [CrossRef]

34. Kusiak, A. Smart manufacturing. Int. J. Prod. Res. 2018, 56, 508-517. [CrossRef]

35. Banks, J.A.C.J.S. Discrete-Event System Simulation; Prentice-Hall, Inc.: Englewood Cliffs, NJ, USA, 1984.

(C) 2019 by the authors. Licensee MDPI, Basel, Switzerland. This article is an open access article distributed under the terms and conditions of the Creative Commons Attribution (CC BY) license (http://creativecommons.org/licenses/by/4.0/). 